Article

\title{
The Beneficial Mechanical and Biological Outcomes of Thin Copper-Gallium Doped Silica-Rich Bio-Active Glass Implant-Type Coatings
}

\author{
George E. Stan ${ }^{1, *(\mathbb{D})}$, Teddy Tite ${ }^{1}$, Adrian-Claudiu Popa ${ }^{1}$, Iuliana Maria Chirica ${ }^{1}$, \\ Catalin C. Negrila ${ }^{1}$, Cristina Besleaga ${ }^{1}{ }^{1 D}$, Irina Zgura ${ }^{1}$, Any Cristina Sergentu ${ }^{1}$, \\ Gianina Popescu-Pelin ${ }^{2}$ D , Daniel Cristea ${ }^{3}$, Lucia E. Ionescu ${ }^{4}$, Marius Necsulescu 4 (D), \\ Hugo R. Fernandes ${ }^{5} \mathbb{D}$ and José M. F. Ferreira ${ }^{5}$ \\ 1 National Institute for Materials Physics, RO-077125 Magurele, Romania; teddy.tite@infim.ro (T.T.); \\ adrian.popa@gmail.com (A.-C.P.); iuliana.bogdan@infim.ro (I.M.C.); catalin.negrila@infim.ro (C.C.N.); \\ cristina.besleaga@infim.ro (C.B.); irina.zgura@infim.ro (I.Z.); anyc@yahoo.com (A.C.S.) \\ 2 National Institute for Lasers, Plasma and Radiation Physics, RO-077125 Magurele, Romania; \\ gianina.popescu@inflpr.ro \\ 3 Faculty of Materials Science and Engineering, Transilvania University of Brasov, 500068 Brasov, Romania; \\ daniel.cristea@unitbv.ro \\ 4 Army Centre for Medical Research, RO-020012 Bucharest, Romania; ionescu.lucia@gmail.com (L.E.I.); \\ mariusnecsulescu@yahoo.com (M.N.) \\ 5 Department of Materials and Ceramics Engineering, CICECO, University of Aveiro, \\ 3810-193 Aveiro, Portugal; h.r.fernandes@ua.pt (H.R.F.); jmf@ua.pt (J.M.F.F.) \\ * Correspondence: george_stan@infim.ro; Tel.: +40-21-241-8128
}

Received: 12 October 2020; Accepted: 18 November 2020; Published: 20 November 2020

\begin{abstract}
Silica-based bioactive glasses (SBG) hold great promise as bio-functional coatings of metallic endo-osseous implants, due to their osteoproductive potential, and, in the case of designed formulations, suitable mechanical properties and antibacterial efficacy. In the framework of this study, the FastOs ${ }^{\circledR} \mathrm{BG}$ alkali-free SBG system $\left(\mathrm{mol}^{\circ}\right.$ : $\mathrm{SiO}_{2}-38.49, \mathrm{CaO}-36.07, \mathrm{P}_{2} \mathrm{O}_{5}-5.61, \mathrm{MgO}-19.24$, $\left.\mathrm{CaF}_{2}-0.59\right)$, with $\mathrm{CuO}(2 \mathrm{~mol} \%)$ and $\mathrm{Ga}_{2} \mathrm{O}_{3}(3 \mathrm{~mol} \%)$ antimicrobial agents, partially substituting in the parent system $\mathrm{CaO}$ and $\mathrm{MgO}$, respectively, was used as source material for the fabrication of intentionally silica-enriched implant-type thin coatings $(\sim 600 \mathrm{~nm})$ onto titanium (Ti) substrates by radio-frequency magnetron sputtering. The physico-chemical and mechanical characteristics, as well as the in vitro preliminary cytocompatibility and antibacterial performance of an alkali-free silica-rich bio-active glass coating designs was further explored. The films were smooth $\left(\mathrm{R}_{\mathrm{RMS}}<1 \mathrm{~nm}\right)$ and hydrophilic (water contact angle of $\sim 65^{\circ}$ ). The SBG coatings deposited from alkali-free copper-gallium co-doped FastOs ${ }^{\circledR}$ BG-derived exhibited improved wear performance, with the coatings eliciting a bonding strength value of $\sim 53 \mathrm{MPa}, \mathrm{Lc} 3$ critical load value of $\sim 4.9 \mathrm{~N}$, hardness of $\sim 6.1 \mathrm{GPa}$ and an elastic modulus of $\sim 127 \mathrm{GPa}$. The $\mathrm{Cu}$ and Ga co-doped SBG layers had excellent cytocompatibility, while reducing after $24 \mathrm{~h}$ the Staphylococcus aureus bacterial development with 4 orders of magnitude with respect to the control situations (i.e., nutritive broth and Ti substrate). Thereby, such SBG constructs could pave the road towards high-performance bio-functional coatings with excellent mechanical properties and enhanced biological features (e.g., by coupling cytocompatibility with antimicrobial properties), which are in great demand nowadays.
\end{abstract}

Keywords: implant coating; bioactive glass; copper doping; gallium doping; mechanical; cytocompatibility; antibacterial 


\section{Introduction}

The last decades witnessed an unprecedented demand for innovative bio-functional materials, capable of not only preventing failure, but also prolonging the life time of orthopaedic/dental implants and bone grafting scaffolds. Silica-based bioactive glasses (SBG) represent a group of reactive biomaterials that possess outstanding features (e.g., bioactivity, osteoproduction, angiogenesis), which are crucial for assuring an excellent interfacial bonding between the host bone tissue and implants [1-7]. The continuous effervescence in the SBG realm, associated with its unique physicalchemical and biological functional properties $[2,5,7]$, is certified by a progressive yearly increase in the number of publications [5].

Most of the reported SBG compositions investigated so far were inspired by the $45 \mathrm{~S} 5$ silicate glass (mol.\%: $\mathrm{SiO}_{2}-46.1, \mathrm{Na}_{2} \mathrm{O}-24.4, \mathrm{CaO}-26.9, \mathrm{P}_{2} \mathrm{O}_{5}-2.6$ ), developed by Hench and his co-workers [8]. Over 30 years since its first implantation in 1985, $45 \mathrm{~S} 5$ bioactive glass has been implanted into 1.5 million patients worldwide under various forms and trade names (e.g., Perioglas ${ }^{\circledR}$, NovaBone ${ }^{\circledR}$, Biogran ${ }^{\circledR}, \operatorname{NovaMin}^{\circledR}$, TeraSphere $\left.{ }^{\circledR}\right)$ [2,5]. Due to their high indices of bioactivity, 45S5-based formulations have been proposed as coating materials for the bio-functionalisation of various metallic titanium-based implants [7,9], to enhance their bone-bonding ability. However, the disparity of the coefficients of thermal expansion (CTE) of $45 \mathrm{~S} 5$ (i.e., $~ 14-17 \times 10^{-6}{ }^{\circ} \mathrm{C}^{-1}$ ) and titanium-based (i.e., $~ 8.5-9.6 \times 10^{-6}{ }^{\circ} \mathrm{C}^{-1}$ ) materials cannot be circumvented with ease [10], and represents a hazard for the long-term mechanical performance of the implant coating. Furthermore, because of the burst release of high concentrations of sodium and overall excessive bio-reactivity [5,11], 45S5 bioactive glass could generate highly alkaline $\mathrm{pH}$ environments, which, in the absence of preconditioning procedures could lead to less than favourable biological outcomes [5,12]. More recently, alkali-free SBGs such as FastOs ${ }^{\circledR} \mathrm{BG}\left(\mathrm{mol} \%\right.$ : $\left.\mathrm{SiO}_{2}-38.49, \mathrm{CaO}-36.07, \mathrm{P}_{2} \mathrm{O}_{5}-5.61, \mathrm{MgO}-19.24, \mathrm{CaF}_{2}-0.59\right)$ have been introduced and acknowledged for their notable performances such as reduced CTEs mismatch, chemical durability, high biomineralization capacity and excellent cytocompatibility $[5,9,13]$.

The possibility to provide new biological functionalities to SBG materials by the inclusion of therapeutic ions within their chemical structure has changed the paradigm in this field, opening new avenues in healthcare and tissue regeneration. Various biologically active elements (e.g., boron, cobalt, magnesium, strontium, zinc) commonly present in the human body have been incorporated in SBGs, as medicinal micronutrients to promote bone regeneration $[2,3,5,14,15]$. These active ions could influence to some extent the structural properties (e.g., morphology, crystallinity, solubility) of these glasses and their biological responses (e.g., degradability, stem cells differentiation and proliferation, osteogenesis, angiogenesis) [5,16-18]. Upon the dissolution of glasses in the physiological environment, these ions are released and induce additional therapeutic effects.

A growing issue in biomedicine is the increased number of implant failures associated to microbial infection. Thus, it is of paramount importance to provide antibacterial properties to the implant by the addition of specific antimicrobial agents. In this context, various studies have reported the benefit of silver and zinc added as antimicrobial agents in SBGs $[5,15,17]$. More recently, gallium (Ga) and copper $(\mathrm{Cu})$ have emerged as a potent new generation of antibacterial ions that may be useful in treating and preventing localized infections [19-29]. Valappil et al. [19] reported on the positive bactericidal effects of gallium-substituted phosphate-based glasses (1-5 mol.\% $\mathrm{Ga}_{2} \mathrm{O}_{3}$ ) against Escherichia coli, Pseudomonas aeruginosa, Staphylococcus aureus, methicillin-resistant S. aureus and Clostridium difficile. The bactericidal activity due to $\mathrm{Ga}^{3+}$ ions was found effective for a $\mathrm{Ga}_{2} \mathrm{O}_{3}$ concentration as low as 1 mol.\% [19]. The potential antimicrobial activity of gallium against E. coli and S. aureus [22], as well as P. aeruginosa [23], has been further confirmed in Ga-substituted SBGs. In relation to CuO-substituted SBGs, recent studies have also demonstrated the potency of $\mathrm{Cu}$ to eradicate the E. coli $[24,25,28]$, P. aeruginosa [28], S. aureus [21,25,27], Salmonella enterica [28] and Staphylococcus epidermidis [25] bacterial strains. Moreover, Cu-substituted SBG-derived glass-ceramic was acknowledged for its excellent antimicrobial efficiency ( $\geq 99.9 \%$ reduction) against $P$. aeruginosa, E. coli, Klebsiella aerogenes and S. aureus [29]. Furthermore, $\mathrm{Cu}$ seems to have the ability to be a fungicide as shown in both 
silica- [26] and apatites-based materials [16]. The association of both $\mathrm{Cu}$ and Ga, as co-dopants in SBGs, can thereby be an attractive way to significantly boost and extend the antimicrobial range of such biomaterials. Furthermore, $\mathrm{Cu}$ and $\mathrm{Ga}$ have other biological benefits, strengthening their potential in healthcare. For example, Cu containing SBGs were reported to encourage the proliferation and differentiation of cells towards the osteogenic phenotype and inhibit osteoclast activity [14,30,31]. A similar behaviour has been reported for Ga ions [23,32,33].

Such results advocate for the investigation of the coupled effects of $\mathrm{Cu}$ and $\mathrm{Ga}$ in alkali-free SBG implant coatings. The benefits that could emerge from the future implementation of co-substituted SBG implant coatings, possessing both effective therapeutic response and adequate mechanical behaviour is nowadays a subject of intense research activity.

In this context, radio-frequency magnetron sputtering (RF-MS), a prominent physical vapour deposition technique, has been selected for the fabrication of implant coatings, due to its proficiency to synthesise high purity uniform films, and the potential to scale-up a refined process to industrial levels [5]. To the best of our knowledge, no studies have been performed yet on RF-MS synthesised SBG films containing $\mathrm{Cu}$ and/or Ga. As aforementioned, the poor interfacial bonding strength of typical SBG films may constitute their Achilles' heel in terms of their clinical applicability. The engineering of SBG film compositions by tuning the network formers/network modifiers ratio could be a strategy to follow when targeting mechanically performant SBG films. Previous attempts have shown that SBG RF-MS layers with a silica content in the range of $~ 55-60$ mol.\% presented excellent pull-off bonding strength values, exceeding $85 \mathrm{MPa}$ [34], thus, being compliant to both recommendations of ISO 13779-2:2018 (minimum value of $15 \mathrm{MPa}$ ) [35] and FDA-STP1196:1994 draft guidance (minimum value of $50.8 \mathrm{MPa}$ ) [36] for implant coatings.

In this work, results concerning thin silica-based implant-type coatings with double addition of potentially antimicrobial $\mathrm{Cu}$ and $\mathrm{Ga}$ agents are presented for the first time, in terms of preliminary mechanical and in vitro biological behaviour. The study could be of importance for an accelerated development of SBG-based implant coatings with excellent mechanical properties, good cell viability and proliferation and high antimicrobial efficiency.

\section{Materials and Methods}

\subsection{Synthesis of Source Cathode Target Materials}

FastOs ${ }^{\circledR} \mathrm{BG}\left(\mathrm{mol} . \%: \mathrm{SiO}_{2}-38.49, \mathrm{CaO}-36.07, \mathrm{P}_{2} \mathrm{O}_{5}-5.61, \mathrm{MgO}-19.24, \mathrm{CaF}_{2}-0.59\right)$ and $\mathrm{Cu}$ and Ga co-substituted FastOs ${ }^{\circledR} \mathrm{BG}$ (mol.\%: $\mathrm{SiO}_{2}-38.49, \mathrm{CaO}-34.07, \mathrm{P}_{2} \mathrm{O}_{5}-5.61, \mathrm{MgO}-16.24, \mathrm{CuO}-2.00$, $\left.\mathrm{Ga}_{2} \mathrm{O}_{3}-3.00, \mathrm{CaF}_{2}-0.59\right)$ glasses were prepared by melt-quenching, following the protocol reported elsewhere $[37,38]$. The glass powders with fine granularity were obtained in a high-speed agate ball mill. The mean particle size of the SBG powders was of $\sim 20-40 \mu \mathrm{m}$, as inferred from the particle size distribution curves obtained by the dynamic light scattering method (Beckman Coulter, model LS 230, Brea, CA, USA) by applying the Fraunhofer optical diffraction model.

Around $25 \mathrm{~g}$ of each SBG powder were mildly pressed (5 kgf) at room-temperature (RT) into copper dishes (diameter $110 \mathrm{~mm}$, depth $3 \mathrm{~mm}$ ) to obtain a magnetron cathode target. The benefits of using such type of targets (i.e., prevention of risk of target cracking and better control over the deposited coating composition) instead of classical ones, melt-poured into moulds, have been advocated in a previous work [39].

\subsection{Deposition by RF-MS of Double-Layered Glass Coatings}

SBG coatings were deposited onto $10 \mathrm{~mm} \times 10 \mathrm{~mm}$ titanium (Mateck GmbH, Jülich, Germany) and silicon (Medapteh, Magurele, Romania) mirror polished substrates with a Vacma UVN-75-R1-type deposition system (Kazan, Soviet Union), equipped with planar magnetron cathodes (110 $\mathrm{mm}$ in diameter) and a RF generator of $1.78 \mathrm{MHz}$. The layer thicknesses were adjusted based on the deposition rates previously determined by spectroscopic ellipsometry. 
The FastOs ${ }^{\circledR} \mathrm{BG}$ and $\mathrm{Cu}$ and Ga substituted FastOs ${ }^{\circledR}$ BG layers with a thickness of $\sim 600 \mathrm{~nm}$ were intentionally enriched in silica by applying the RF-MS protocol defined in Reference [40], with fused silica plates (Präzisions Glas \& Optik GmbH, Iserlohn, Germany) positioned on the racetrack (annular zone of maximum sputtering erosion). All depositions were carried out at an argon pressure of $0.4 \mathrm{~Pa}$ and a target-to-substrate distance of $35 \mathrm{~mm}$.

\subsection{Physico-Chemical Characterization}

The films' thickness was determined by spectroscopic ellipsometry (SE) using a Woollam apparatus (Lincoln, NE, USA) equipped with a HS-190 monochromator. The measurements were made at $65^{\circ}$, $70^{\circ}$ and $75^{\circ}$ incidence angles, with a resolution of $3^{\circ}$, in the $400-1700 \mathrm{~nm}$ spectral range. The SBG films were modelled using a Cauchy dispersion relation [41,42].

As their morphology was extremely smooth, the topological features of the SBG films were explored by atomic force microscopy (AFM), using an NT-MDT NTEGRA NanoLaboratory Probe system (Moscow, Russia). AFM images were recorded in non-contact mode on $5 \times 5 \mu \mathrm{m}^{2}$ areas.

The elemental compositions of the source SBG materials and derived RF-MS coatings were estimated by energy dispersion X-ray spectroscopy (EDXS) using the EDAX Inc. (Mahwah, NJ, USA) micro-probe attached to a scanning electron microscope, operated at an acceleration voltage of $10 \mathrm{kV}$. The measurements were made on at least four randomly chosen sample regions with areas of $250 \times 250 \mu^{2}$. Only the elemental (in at.\%) concentrations of $\mathrm{Si}, \mathrm{Ca}, \mathrm{P}, \mathrm{Mg}, \mathrm{Cu}$ and $\mathrm{Ga}$ were inferred and will be further represented as arithmetic means \pm standard deviations, since the quantification of lighter elements (i.e., oxygen and fluorine) by EDXS is prone to large errors [43].

The chemical state of SBG elements was analysed by X-ray photoelectron spectroscopy (XPS) using a Specs GmbH Multimethod System (Berlin, Germany). The XPS system is equipped with a Phoibos 150 hemispherical energy analyser with a multi-element two-stage transfer lens and a nine channeltron detector array. The photo-emission studies were carried out at a pressure of $\sim 10^{-7} \mathrm{~Pa}$, using a XR-50M Al K $\alpha(1486.7 \mathrm{eV})$ source coupled to a FOCUS500 single-crystal quartz monochromator. The X-ray source was set at $300 \mathrm{~W}$. A pass energy of $20 \mathrm{eV}$ was used for the high-resolution core level spectral recordings. An ultimate resolution of $0.44 \mathrm{eV}$ (given as full width at half maximum of the $\mathrm{Ag}$ $3 \mathrm{~d}_{5 / 2}$ peak recorded with a pass energy of $20 \mathrm{eV}$, using monochromated $\mathrm{Al} \mathrm{K} \alpha$ radiation, for a clean silver film) can be attained. The sample neutralization during the measurements was achieved by using a flood gun, working at acceleration energy of $1 \mathrm{eV}$ and an emission current of $0.1 \mathrm{~mA}$. In order to remove surface contaminants due to environmental/adventitious carbonaceous species, an in situ preliminary argon ions etching (using a Specs IQE11/35 ion gun) session was performed for 5 min, at an energy of $3 \mathrm{keV}$ and a pressure of $1 \times 10^{-3} \mathrm{~Pa}$. The background was subtracted using the Shirley method. The fitting of spectra was performed with a dedicated software Spectral Data Processor using Voigt functions, version 3.0 (XPS International, Mountain View, CA, USA).

The structure of the SBG films was investigated by Fourier transform infrared (FTIR) spectroscopy measurements with a Perkin Elmer Spectrum BX II (Waltham, MA, USA) spectrophotometer. The FTIR spectroscopy investigations were performed in transmission mode, on films deposited onto infrared transparent Si substrates. The spectra were acquired in the wave numbers range of $4000-400 \mathrm{~cm}^{-1}$, at a resolution of $4 \mathrm{~cm}^{-1}$, and represent the average of 32 individual scans.

The surface free energy of the SBG films was determined based on static contact angle measurements (performed at least in triplicate), using a Drop Shape Analysis system (model DSA 100) from Krüss GmbH (Hamburg, Germany) and two standard solutions, one polar (i.e., water) and one dispersive (i.e., diiodomethane). The measurements were performed at RT, with the two solutions being precisely poured in droplets on the sample surface via a needle attached to a syringe pump controlled by the DSA $3{ }^{\circledR}$ software (Hamburg, Germany). The volume of the droplet (i.e., $1 \mu \mathrm{L}$ ) and the distance from the droplet to the sample was kept constant throughout the experiments. The contact angles were estimated, and the surface energy was calculated using the Owens-Wendt method [44]. 
The bonding strength of the films to the Ti substrate was estimated by the pull-off test method, using a DFD ${ }^{\circledR}$ Instruments PAThandy adhesion tester (Kristiansand, Norway), with a maximum force of $1 \mathrm{kN}$, and applying the testing procedure described in References [45,46], conducted in accordance with the ISO 4624:2016 [47] and ASTM D4541-17:2017 [48] standards.

The nano-mechanical properties were evaluated by nano-indentation tests using an NHT-2 CSM Instruments/Anton Paar GmbH (Peseux, Switzerland), equipped with a Berkovich diamond nano-indenter. The Oliver-Pharr method [49] was used to determine the modulus of elasticity (E) and hardness $(\mathrm{H})$ of films from the load-displacement curves. The penetration depth was chosen in such a manner to minimize as much as possible the influence of the substrate on the results.

The scratch and wear resistances were evaluated with a dedicated MicroScratch Tester from CSM Instruments (Peseux, Switzerland), equipped with a diamond Rockwell conical indenter. The scratch test involves the passage (with a progressive applied load) of the Rockwell indenter, on the surface of the sample to result in a scratch. The load applied on the conical indenter increases progressively producing elastic and plastic deformations of the layer-substrate systems, which are becoming more and more pronounced. Conventionally, three critical load values are detected: (i) the load which causes the first deterioration of the cohesion of the layer (first cracks) (Lc1); (ii) the load leading to the partial removal of the coating (partial delamination) (Lc2); and (iii) the applied load that causes the removal of at least $50 \%$ of the deposited layer (Lc3) [50,51]. The device is equipped with sensors that measure and record the acoustic emissions during the scratch process, the penetration depth and the friction force. The adhesion to the substrate, as well as the cohesion of the SBG layers were evaluated according to the European standard EN1071-3/2005: “Advanced technical ceramics-Methods of test for ceramic coatings-Part 3: Determination of adhesion and other mechanical failure modes by a scratch test" [52] and the "Scratch test atlas of failure modes" guide [53]. The abrasive wear behaviour of the SBG films was determined using the same MicroScratch Tester, by using a heat-treated steel tip (Rockwell conical geometry) $(\mathrm{HV}=1000)$ to employ a friction torque. While the sample is in translation motion, the frictional forces that occur between the sample and the tip are measured using a Linear Variable Differential Transformer sensor (CSM Instruments, Peseux, Switzerland). Five incremental load values (i.e., 1, 2, 3, 4 and $5 \mathrm{~N}$ ) were used, with 10 passages per load at a travel speed of $4 \mathrm{~mm} / \mathrm{min}$. The wear track section areas for each sample and each applied load were assessed by transversal scanning with the same MicroScratch tester, using a $0.03 \mathrm{~N}$ applied load. The wear coefficient was calculated on the basis of the wear volume loss at the maximum used load $(5 \mathrm{~N})$, as function of the total test length.

\subsection{In Vitro Preliminary Biological Testing}

Prior to each in vitro test all samples were sterilized by applying a dry-heat procedure performed at $180{ }^{\circ} \mathrm{C}$ for $1 \mathrm{~h}[54,55]$.

\subsubsection{Antibacterial Tests}

The antimicrobial activity against the Staphylococcus aureus (ATCC ${ }^{\circledR}$ 6538) bacterial strain was performed according to the ISO 22196:2011 standard [56]. Briefly, suspensions of S. aureus in nutritional broth (Sanimed International Impex SRL, Bucharest, Romania) were prepared at a concentration of $10^{6} \mathrm{CFU} / \mathrm{mL} .50 \mu \mathrm{L}$ of nutrient broth containing $5 \times 10^{3}$ viable CFUs were deposited on the surface of the specimens. Then, an inert sterile plastic film was placed over the samples and the plates were inserted into the incubator. After $24 \mathrm{~h}, 3 \mathrm{~mL}$ of nutrient broth was added to each well and the samples were completely scraped with a dedicated sterile rubber scrubber to detach any bacterial cells that could be encapsulated in the biofilm. 10-serial dilutions were prepared for each studied situation, and from each sample dilution two simple agar plates were seeded with $1 \mathrm{~mL}$ of the inoculum. After $24 \mathrm{~h}$ of incubation, the colonies on the plates were counted. The number of viable CFUs developed after $24 \mathrm{~h}$ in the presence of control and SBG coatings were calculated with the formula: $3 \times$ dilution factor $\times$ (average number of colonies on plates). 


\subsubsection{Cytocompatibility Assays}

The cytocompatibility tests were performed on mouse fibroblast cells NIH/3T3 (ATCC ${ }^{\circledR}$ CRL-1658 ${ }^{\mathrm{TM}}$ ) in accordance with ISO 10993-5:2009 [57]. The protocol was refined in previous studies [58,59] and can be briefly summarised as follows:

Cell culture preparation: When cells reached confluence, they were detached with trypsin, collected and centrifuged at $200 \times g$ for 10 min after trypsin inactivation with soybean trypsin inhibitor. After centrifugation, the cells were re-suspended, and their number was adjusted to $10^{5}$ cells $/ \mathrm{mL}$. On each sample, $10^{4}$ cells were seeded in $100 \mu \mathrm{L}$ medium. The plates were inserted into the incubator for cell adhesion. After $4 \mathrm{~h}, 400 \mu \mathrm{L}$ of the Dulbecco's Modified Eagle Medium/Nutrient Mixture F-12 (DMEM-F12) (Sigma Aldrich, St. Louis, MO, USA) culture medium supplemented with $10 \%$ foetal bovine serum, was added. After $24 \mathrm{~h}, 50 \mu \mathrm{L}$ of medium was collected to investigate the cytotoxic effect by the lactate dehydrogenase (LDH) assay (Thermo Scientific, Waltham, MA, USA).

Cell morphology: Epifluorescence microscopy was used to assess the morphology of 3T3 cells on the surface of the SBG samples. After $24 \mathrm{~h}$ of culture, the cells were fixed with $4 \%$ paraformaldehyde in phosphate buffered saline (PBS) for $15 \mathrm{~min}$ and then washed three times for $5 \mathrm{~min}$ with PBS. The cells were then incubated for $1 \mathrm{~h}$ at RT with $100 \mu \mathrm{L}$ Phalloidin-AlexaFluor546 (Invitrogen, Carlsbad, CA, USA). After a series of three PBS washes of $10 \mathrm{~min}$ each, the cells were incubated with $1 \mu \mathrm{g} / \mathrm{mL} 4^{\prime}$, 6-diamidino-2-phenylindole (DAPI) (Sigma Aldrich, St. Louis, MO, USA). After a final washing step in PBS (two times for $10 \mathrm{~min}$ ) and double distilled water (one time), the cells were imaged in a standard fluorescence microscope Leica DM6 B apparatus (Wetzlar, Germany), equipped with a Leica DFC 9000 GT camera and appropriate fluorescence objectives and filters.

Cell proliferation: The cellular proliferation was evaluated using the MTS (3-(4, 5-dimethyl thiazol-2-yl) 5-(3-carboxymethoxyphenyl)-2-(4-sulfophenyl)-2H-tetrazolium) kit (Promega Corporation, Madison, WI, USA). At the time of culturing, three wells were used to investigate the mitochondrial activity at $\mathrm{T}_{0}$ moment. Three hours after seeding, the cells were analysed under an inverted microscope to observe their adhesion. The well was filled with $400 \mathrm{~mL}$ of fresh complete cell culture medium and then $80 \mu \mathrm{L}$ MTS buffer was added. After $1 \mathrm{~h}$ in the incubator, $120 \mu \mathrm{L}$ of medium was transferred to 96-wells plates and the absorbance was read at $490 \mathrm{~nm}$ using a Zenyth 3100 multimodal microplate reader (Anthos Labtec Instruments, Salzburg, Austria). The optical density (OD) at the $\mathrm{T}_{0}$ seeding moment was calculated, and then was used to quantify the cell proliferation after $24 \mathrm{~h}$.

Cell death: The cytotoxicity of SBG films was investigated using an LDH assay kit. After $24 \mathrm{~h}$ of cell culturing, $50 \mu \mathrm{L}$ of the supernatant medium was collected and transferred into a 96-well microplate. An amount of $50 \mu \mathrm{L} \mathrm{LDH}$ substrate solution, prepared according to the manufacturer's instructions was added to each well. After $30 \mathrm{~min}$ of incubation, the reaction was stopped with $50 \mu \mathrm{L}$ of stop buffer. The absorbance values at 490 and $620 \mathrm{~nm}$ were read with the Zenyth 3100 apparatus and the result was considered as the difference between the absorption at $490 \mathrm{~nm}$ and that at $620 \mathrm{~nm}$ (taken as a standard). The cut-off value was obtained in the presence of the fresh culture medium.

\subsection{Statistical Analysis}

The statistical analysis was performed using the unpaired two-tailed Student's $t$-test, with the differences being considered significant when $p<0.05$.

\section{Results and Discussion}

\subsection{Physico-Chemical Analyses}

\subsubsection{AFM Morphological Examination}

The AFM microscopic investigations revealed that the SBG films, regardless of their composition (i.e., FastOs ${ }^{\circledR} \mathrm{BG}$-Figure 1a or Cu\&Ga-FastOs ${ }^{\circledR} \mathrm{BG}$-derived-Figure 1b), had a highly similar morphology, being smooth (i.e., root-mean-square roughness of $<1 \mathrm{~nm}$ ) and compact. The films were 
composed of dome-shaped nano-sized particles with diameters within the $\sim 15-20 \mathrm{~nm}$ narrow range, characteristic to amorphous magnetron sputtered structures.

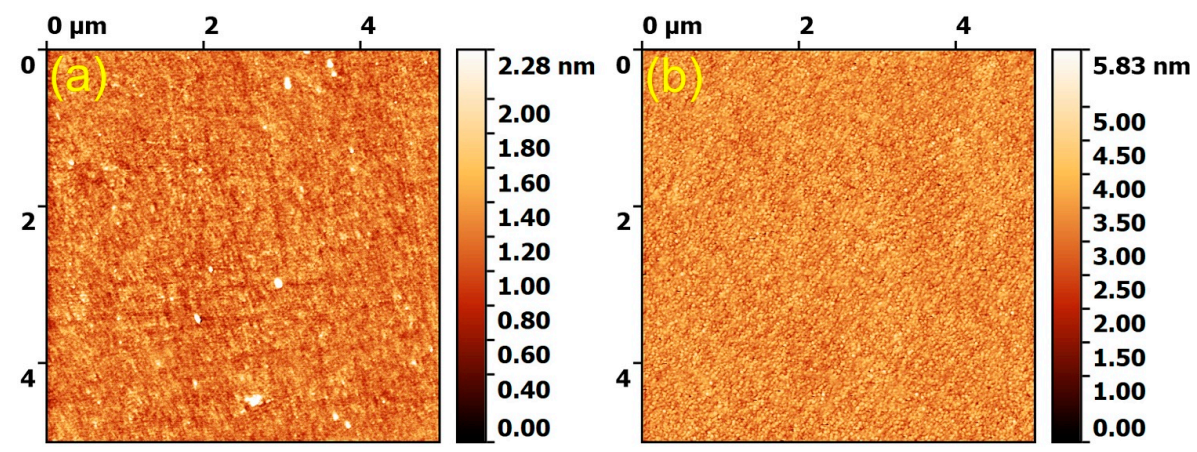

Figure 1. 2D atomic force microscopy (AFM) images recorded on $5 \times 5 \mu \mathrm{m}^{2}$ surface areas of the (a) FastOs ${ }^{\circledR}$ BG- and (b) Cu\&Ga-FastOs ${ }^{\circledR}$ BG-derived films.

\subsubsection{EDXS Compositional Analysis}

The comparative elemental compositions (in at.\%) of the source SBG materials and of the FastOs ${ }^{\circledR}$ BG- and Cu\&Ga-FastOs ${ }^{\circledR}$ BG-derived layers, as estimated by EDXS analysis, are presented in Figure 2. The results showed that the SBG films were, as intended, successfully enriched in $\mathrm{Si} / \mathrm{SiO}_{2}$ ( 53-54 at.\%/ 56-57 mol.\%) in both coating cases, at the expense of $\mathrm{Ca}$ and $\mathrm{Mg}$, which recorded a concentration decrease of $\sim 23-32 \%$ and $~ 18-24$ at.\%, respectively. The decrease (with 41-48 at.\%) of the $\mathrm{P}$ concentration is a characteristic to RF-MS processes, and it is likely linked to the higher volatility of $\mathrm{P}_{2} \mathrm{O}_{5}$ (and associated with its relatively low sublimation latent heat) compared to the other oxide glass constituents $[40,60]$. The $\mathrm{Cu}$ and $\mathrm{Ga}$ contents of the $\mathrm{Cu \& Ga-FastOs}{ }^{\circledR} \mathrm{BG}$ source biomaterial were well-transferred into the RF-MS films (no statistical significant differences being determined, $p>0.05$ ).

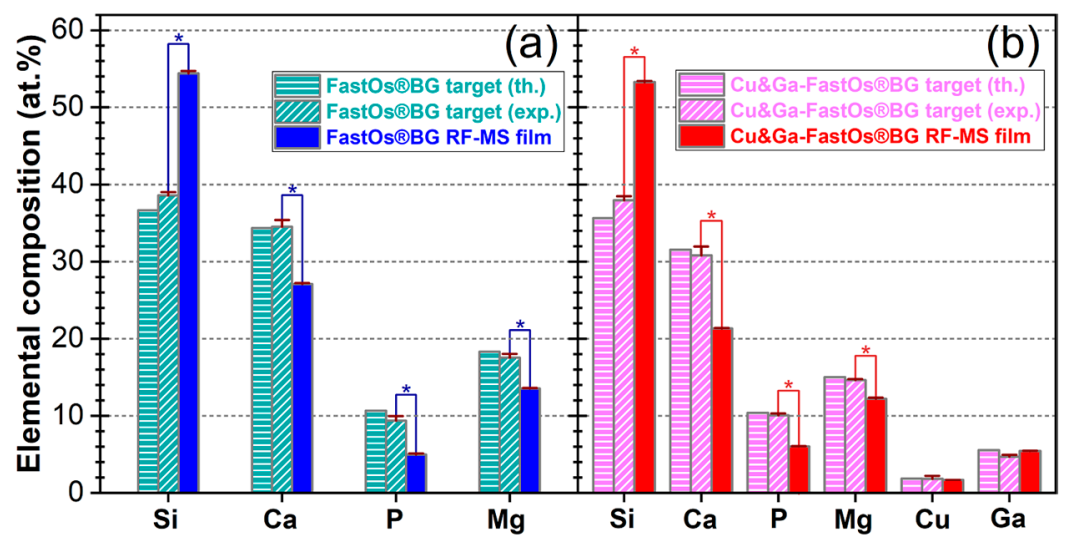

Figure 2. Comparative elemental composition (in at.\%) of the magnetron cathode targets and the deposited silica-rich films: (a) FastOs ${ }^{\circledR}$ BG- and (b) Cu\&Ga-FastOs ${ }^{\circledR}$ BG-based materials. The quantification of oxygen and fluorine was not performed because of the inaccuracy of EDXS analysis method with respect to light elements $(Z<11)[43] .{ }^{*} p<0.05$, statistically significant differences, as determined by using an unpaired two-tailed Student's $t$-test.

\subsubsection{XPS Chemical State Examination}

The high-resolution core electron XPS spectra of the Si 2p, Ca 2p, P 2p, Mg 2p, Cu 2p $3 / 2$, Ga 2p $p_{3 / 2}$ and $\mathrm{O} 1 \mathrm{~s}$ levels of the source materials and derived RF-MS films are presented comparatively in Figure $3 \mathrm{a}-\mathrm{d}, \mathrm{e}-\mathrm{h}, \mathrm{i}-\mathrm{l}, \mathrm{m}-\mathrm{p}, \mathrm{q}-\mathrm{s}, \mathrm{r}-\mathrm{t}$, and $\mathrm{u}-\mathrm{x}$, respectively. The binding energy positions of the $\mathrm{Si}$ 2p ( 101.9-102.6 eV), Ca 2p $\mathrm{p}_{3 / 2}(\sim 347.5-347.6 \mathrm{eV}), \mathrm{P} 2 \mathrm{p}_{3 / 2}(\sim 133.0-133.4 \mathrm{eV}), \mathrm{Mg} 2 \mathrm{p}(\sim 50.1-50.3 \mathrm{eV})$ 
correlated with the Auger parameter calculated as the binding energy of $\mathrm{Mg} 2 \mathrm{p}+$ kinetic energy of $\mathrm{Mg}$ KLL ( 1230.0-1230.7 eV) lines (data not shown), disclosed their complete oxidation [61] in the case of both source materials and derived SBG films.
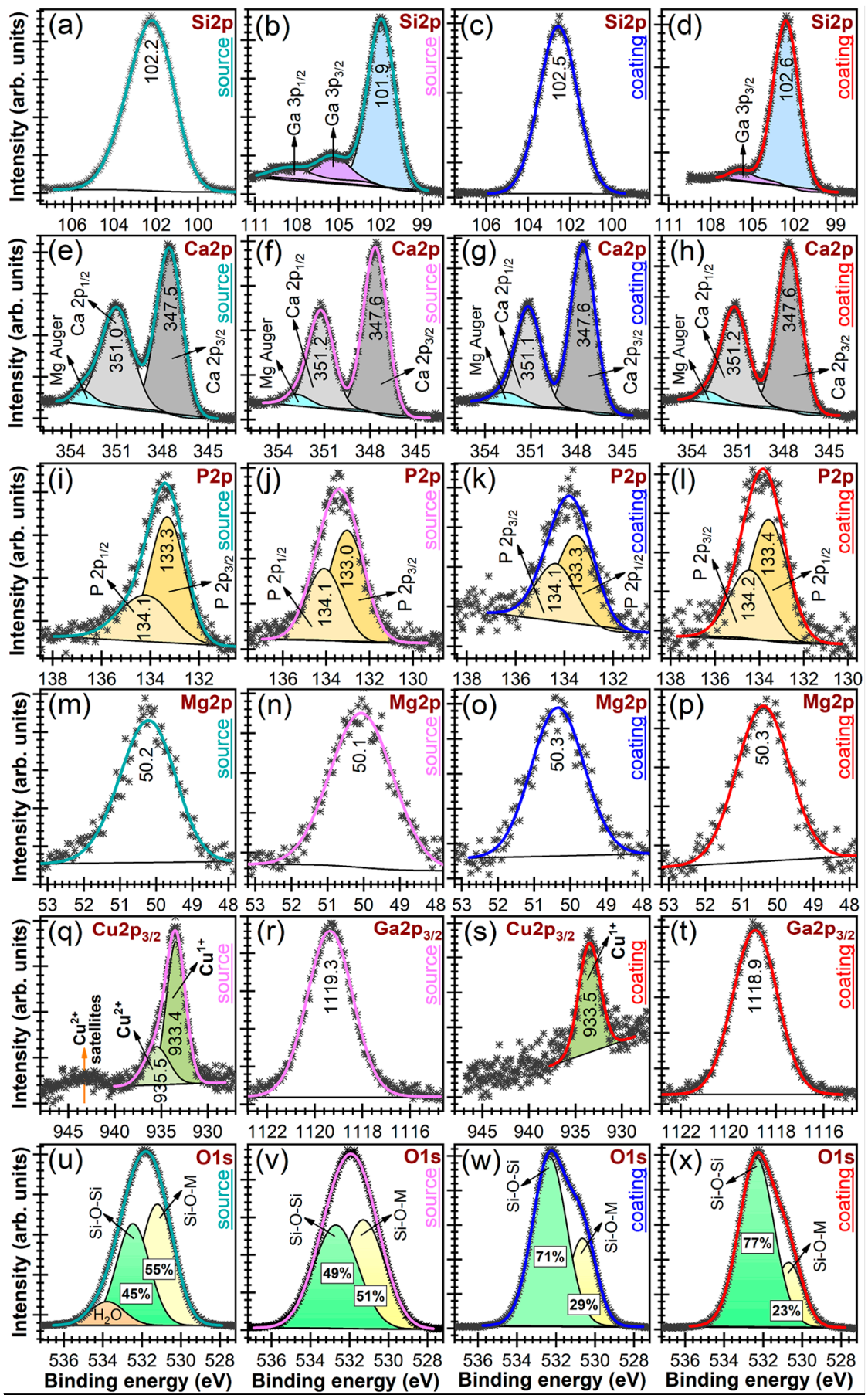

Figure 3. High resolution XPS spectra of the (a-d) Si 2p, (e-h) Ca 2p, (i-1) P 2p, (m-p) Mg 2p, (q, s) $\mathrm{Cu} 2 \mathrm{p}_{3 / 2},(\mathbf{r}, \mathbf{t}) \mathrm{Ga} \mathrm{3} \mathrm{p}_{3 / 2},(\mathbf{u}-\mathbf{x}) \mathrm{O}$ 1s core photoelectron levels, recorded for the $(\mathbf{a}, \mathbf{c}, \mathbf{e}, \mathbf{g}, \mathbf{i}, \mathbf{k}, \mathbf{m}, \mathbf{o}, \mathbf{u}, \mathbf{w})$ FastOs ${ }^{\circledR} B G$ and $(\mathbf{b}, \mathbf{d}, \mathbf{f}, \mathbf{h}, \mathbf{j}, \mathbf{l}, \mathbf{n}, \mathbf{p}, \mathbf{q}-\mathbf{t}, \mathbf{v}, \mathbf{x})$ Cu\&Ga-FastOs ${ }^{\circledR} \mathrm{BG}(\mathbf{a}, \mathbf{b}, \mathbf{e}, \mathbf{f}, \mathbf{i}, \mathbf{j}, \mathbf{m}, \mathbf{n}, \mathbf{q}, \mathbf{r}, \mathbf{u}, \mathbf{v})$ source materials and $(\mathbf{c}, \mathbf{d}, \mathbf{g}, \mathbf{h}, \mathbf{k}, \mathbf{l}, \mathbf{o}, \mathbf{p}, \mathbf{s}, \mathbf{t}, \mathbf{w}, \mathbf{x})$ derived films. Symbols: experimental spectrum, Solid line: fit sum. Filled area curves: spectral components.

The Ga $2 \mathrm{p}_{3 / 2}$ levels are situated at $\sim 1119.3$ and $\sim 1118.9 \mathrm{eV}$ for the cathode target and RF-MS film (Figure $3 r, t$ ), respectively, unveiling the $3^{+}$oxidation state of gallium $[61,62]$. The core electron spectra 
collected in the region of the $\mathrm{Cu} 2 \mathrm{p}_{3 / 2}$ peak indicated that the $\mathrm{Cu}$ is found in both $1+(\sim 933.4 \mathrm{eV})$ and $2+(\sim 935.5 \mathrm{eV})$ oxidation states in the case of the Cu\&Ga-FastOs ${ }^{\circledR} \mathrm{BG}$ source material (Figure 3q) [61]. The presence of $\mathrm{Cu}^{2+}$ in the melt-quenched glass is also supported by the lower intensity broad peak, situated at higher binding energies and ascribed to the $\mathrm{Cu}^{2+}$ satellites [61]. In the case of the Cu\&Ga-FastOs ${ }^{\circledR} \mathrm{BG}$-derived RF-MS films, the $\mathrm{Cu}^{2+}$ satellites were difficult to emphasize due to the low intensity of the peaks and consequently higher noise/signal ratio. The $\mathrm{Cu}^{2+}$ reduction to $\mathrm{Cu}^{+}$ oxidation state could be related to the lower thermodynamic driving force for the formation of $\mathrm{CuO}$ with respect to $\mathrm{Cu}_{2} \mathrm{O}$, as the Gibbs free energy of oxidation is higher for the former [63]. As a matter of fact, the Gibbs free energy of formation of the $\mathrm{Cu}$ oxides is lower with respect to all the other glass components (i.e., $\mathrm{SiO}_{2}, \mathrm{CaO}, \mathrm{P}_{2} \mathrm{O}_{5}, \mathrm{MgO}, \mathrm{Ga}_{2} \mathrm{O}_{3}$ ) [63].

Two components were disclosed by the peak separation procedure applied to the $\mathrm{O} 1 \mathrm{~s}$ spectra of the glass source materials and RF-MS films (Figure $3 u-x$ ). The higher energy component (positioned at $\sim 532.3-532.8 \mathrm{eV}$ ) is assigned to the $\mathrm{Si}-\mathrm{O}-\mathrm{Si}$ bonds contribution (bridging oxygen bonds), whilst the lower binding energy one (centred at $\sim 530.7-531.3 \mathrm{eV}$ ) is associated to the oxygen bonds with metal species (i.e., $\mathrm{Si}-\mathrm{O}-\mathrm{M}$ bonds $(\mathrm{M}=$ metal ions in the glass), non-bridging oxygen bonds) [64,65]. An additional third minor $\mathrm{O} 1 \mathrm{~s}$ component, positioned at a higher binding energy $(\sim 533.8 \mathrm{eV})$, was evidenced in the case of the FastOs ${ }^{\circledR} \mathrm{BG}$ target material only (Figure $3 \mathrm{u}$ ). This third component can be ascribed to the adsorbed water $[58,61]$, and is determined by hydroscopic character of the SBG. The Si-O-Si/Si-O-M ratio was dramatically increased in the case of RF-MS coatings with respect to the source materials (Figure $3 \mathbf{u}-\mathbf{x}$ ), as consequence of their intentional increase in Si concentration (Figure 2). In both the source material and RF-MS derived coating cases, the incorporation of $\mathrm{Cu}$ and $\mathrm{Ga}$ into the glass structure induced a slight increase of $\mathrm{Si}-\mathrm{O}-\mathrm{Si} / \mathrm{Si}-\mathrm{O}-\mathrm{M}$ ratio, which suggested an improvement of the network connectivity.

\subsubsection{FTIR Spectroscopy Structural Investigation}

When network modifiers are incorporated into SBGs, the covalent $\mathrm{Si}-\mathrm{O}-\mathrm{Si}$ bonds are broken, and non-bridging oxygen atoms (NBO) are formed. The silica-based glass network becomes disrupted through the creation of ionic bonds between NBOs and modifier cations [5]. The network connectivity is directly influencing the stability and durability of SBG in contact with the intercellular fluids [5]. The short-range order in oxide glasses is generally quantified by the $Q^{\mathrm{n}}$ notation, in which $Q$ represents a network-former polyhedron (in the case of $\mathrm{SBG},\left[\mathrm{SiO}_{4}\right]$ ), whilst $n$ corresponds to the number of associated bridging oxygen atoms (BOs).

The FTIR spectra of the simple and Cu \& Ga substituted SBG source biomaterials, and of the RF-MS derived coatings are presented together in Figure 4a-c. Both the FastOs ${ }^{\circledR}$ BG-based source materials (Figure 4a) were characterized by the presence of large IR absorption bands with four maxima positioned at (i) $\sim 1181 \mathrm{~cm}^{-1}$, (ii) $\sim 1030 \mathrm{~cm}^{-1}$, (iii) $\sim 950 \mathrm{~cm}^{-1}$ and (iv) $855 \mathrm{~cm}^{-1}$ appertaining to the asymmetric stretching $\left(v_{\text {as }}\right)$ vibrational modes of: $(\mathrm{i}+\mathrm{ii})$ of the $\mathrm{Si}-\mathrm{O}-\mathrm{Si}$ bonds in all the silicate tetrahedrons, $\mathrm{TO}_{3}$ (Transverse-Optical) and $\mathrm{LO}_{3}$ (Longitudinal-Optical) modes, respectively, and of $\mathrm{Si}-\mathrm{O}$ bonds in (iii) $\mathrm{Q}^{2}+\mathrm{Q}^{3}$ (with one and two NBOs) and (iv) $\mathrm{Q}^{0}+\mathrm{Q}^{1}$ (with three and four NBOs) units [9,66-68]. The lower intensity band at $\sim 749 \mathrm{~cm}^{-1}$ is assigned to the symmetrical stretching $\left(v_{\mathrm{s}}\right)$ vibrations of $\mathrm{Si}-\mathrm{O}$ bonds. The incorporation of $\mathrm{Cu}$ and $\mathrm{Ga}$ into the composition of the parent FastOs ${ }^{\circledR} \mathrm{BG}$ material induced an improvement of the glass network connectivity, as suggested by the small intensity reduction of the $\mathrm{Q}^{2}+\mathrm{Q}^{3} \mathrm{NBO}$ band (at $\sim 950 \mathrm{~cm}^{-1}$ ), while the intensity of the Si-O-Si band (at $\sim 1030 \mathrm{~cm}^{-1}$ ) remained constant (Figure $4 \mathrm{~b}$ ).

The successful increase of the network modifiers concentration (Figure 2) of SBG RF-MS coatings had as consequences the (i) disappearance of the band at $\sim 855 \mathrm{~cm}^{-1}$ (associated with the $v_{\text {as }} \mathrm{Q}^{0}+$ $\mathrm{Q}^{1}$ band) (Figure $4 \mathrm{c}$ ), together with a (ii) pronounced decrease in intensity of the $v_{\text {as }} \mathrm{Q}^{2}+\mathrm{Q}^{3}$ band (Figure 4b). 

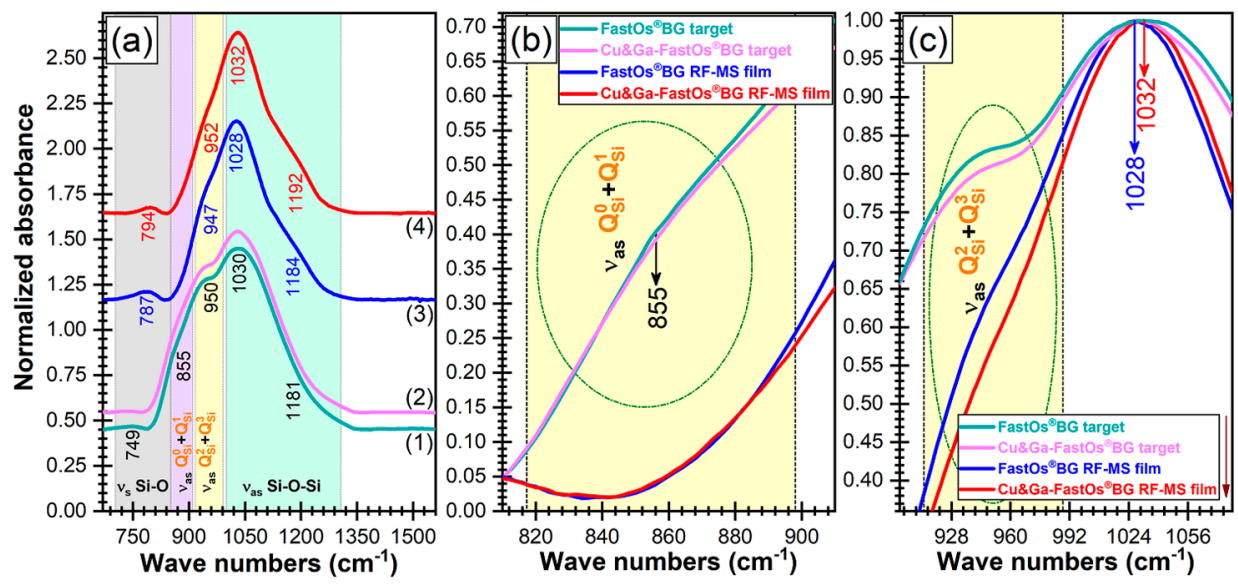

Figure 4. (a) FTIR spectra of the (1) FastOs ${ }^{\circledR} \mathrm{BG}$ and (2) Cu\&Ga-FastOs ${ }^{\circledR} \mathrm{BG}$ melt-quenched glass powders, and (3) FastOs ${ }^{\circledR}$ BG- and (4) Cu\&Ga-FastOs ${ }^{\circledR}$ BG-derived RF-MS layers; Insets highlighting the main structural modifications occurring in the spectral regions of the (b) $v_{\text {as }} Q^{0}+Q^{1}$ and (c) $v_{\text {as }} Q^{2}$ $+\mathrm{Q}^{3}$ vibration bands.

The incorporation of $\mathrm{Cu} \& \mathrm{Ga}$ therapeutic ions into the SBF RF-MS film structure led to minor structural changes that advocate for a slight polymerization of this type of coating with respect to the FastOs ${ }^{\circledR}$ BG-derived one (similarly to the trends experienced by the source materials). This was hinted by the minor intensity decrease and position shift of the absorption band associated with $v_{\text {as }}$ vibration modes of bonds in the $\mathrm{Q}^{3}+\mathrm{Q}^{2}$ units (Figure $4 \mathrm{~b}$ ). Concurrently, the IR absorption bands generated by $\mathrm{Si-O}-\mathrm{Si}$ bonds experienced a slight blue-shift (Figure $4 \mathrm{a}, \mathrm{b}$ ). This is in agreement with the afore-presented XPS results (Figure $3 \mathrm{u}-\mathrm{x}$ ), which indicated a higher $\mathrm{Si}-\mathrm{O}-\mathrm{Si} / \mathrm{Si}-\mathrm{O}-\mathrm{M}$ ratio in the case of the Cu\&Ga-FastOs ${ }^{\circledR} \mathrm{BG}$-based materials. Since the network former content $(\mathrm{Si}+\mathrm{P})$ is the same $(\sim 59.3 \%)$ for both type of films, and the concentration of well-known network modifiers $(\mathrm{Ca}+\mathrm{Mg}+\mathrm{Cu})$ is higher ( $\sim 40.6 \%$ vs. $\sim 35.2 \%$ ) for the FastOs ${ }^{\circledR}$ BG-derived structure (Figure 2 ), it is suggested that at least part of $\mathrm{Ga}$ ions act as network formers. The network former role of $\mathrm{Ga}$ is not unprecedented [23] in SBGs. However, for the time being this should be treated as merely a hypothesis, with the clarification of Ga role within the RF-MS SBG films' structure demanding further insightful analyses, which will be the focus of future systematic studies.

\subsubsection{Surface Energy Measurements}

The evolution of surface free energy (and their polar and dispersive components as nominal values and ratios) and water contact angles (CA), recorded for the bare Ti and simple and $\mathrm{Cu}-\mathrm{Ga}$ doped SBG coatings are shown in Figure 5a,b. The variation of the polar and dispersive components of the surface free energy (SFE, $\gamma_{\text {tot }}$ ), and thus the hydrophilic/hydrophobic character, can unveil prospective biofunctional traits of a scrutinized material/construct $[69,70]$. The polar component $\left(\gamma_{p}\right)$ is generated by the chemical bonds/interactions (e.g., dipole-dipole interactions) within the material, whilst the dispersive component $\left(\gamma_{\mathrm{d}}\right)$ is linked to the movement of electrons around atoms/molecules and temporary variation in the electron density with associated temporary dipoles [71]. SFE is known to play a major role in biocompatibility, leading to the arrangement of functional groups and electrical charges on the surface of the biomaterials in contact with the living environment, and thus, govern the first interactions with the intercellular fluid and the adherence of cells $[70,72,73]$. 


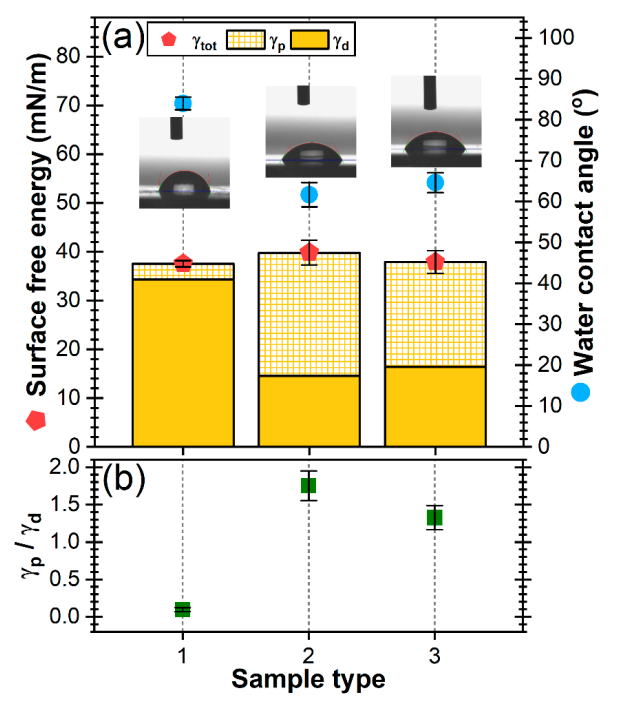

Figure 5. Evolution of the (a) surface free energy values $\left(\gamma_{\mathrm{tot}}\right)$, its polar $\left(\gamma_{\mathrm{p}}\right)$ and dispersive $\left(\gamma_{\mathrm{d}}\right)$ components, water contact angle average values and (b) ratios of the polar $\left(\gamma_{\mathrm{p}}\right) /$ dispersive $\left(\gamma_{\mathrm{d}}\right)$ components of the surface free energy, for the (1) bare Ti and (2) FastOs ${ }^{\circledR}$ BG-derived and (3) Cu\&Ga-FastOs ${ }^{\circledR}$ BG-derived RF-MS coatings.

The SFE values of both the bare and FastOs ${ }^{\circledR}$ BG- and Cu\&Ga-FastOs ${ }^{\circledR}$ BG-derived coated Ti specimens were found to be situated in a rather narrow range of $\sim 37-40 \mathrm{mN} / \mathrm{m}(p>0.05$, thus, without statistical significant differences) (Figure 5a). However, the weight of the polar and dispersive components of the SFE significantly differed in the case of the silica-rich SBG coated Ti, with the polar component becoming dominant (Figure $5 b$ ). While the contact angle (CA) value with water does not change upon the incorporation of $\mathrm{Cu} \& \mathrm{Ga}$ into the SBG film structure (CA $\approx 62-64^{\circ}, p>0.05$ ), in the case of $\mathrm{Ti}$, a CA value towards the hydrophobic domain (i.e., $84^{\circ}$ ) was obtained. It is important to note that in the case of implant surfaces, many studies indicated that an optimal wettability range, capable of augmenting the cellular response (i.e., adhesion, proliferation and cytoskeleton organisation), is the $60-80^{\circ}$ one [73-75]. Thereby, from this point of view favourable premises existed for a positive biological response in the case of the proposed silica-rich bioglass implant coating design.

\subsection{Mechanical Performance Characterization}

The first mechanical assessment consisted in the evaluation of the bonding strength of the SBG-based coating by the pull-off test. The tensile tests yielded similar values for both simple and $\mathrm{Cu}-\mathrm{Ga}$ doped SBG coatings (Figure 6a), with average bonding strength values of $\sim 53-55 \mathrm{MPa}(p>0.05$, thus, without statistically significant differences). The recorded bonding strength values are situated above the limits imposed for implant coatings by the ISO 13779-2:2018 [35] (i.e., $15 \mathrm{MPa}$ ), and are close to those recommended by the FDA—STP1196 draft guidance (i.e., 50.8 MPa) [36].

Further, the mechanical properties of the SBG films were evaluated by scratch, nano-indentation and wear tests.

During the scratch tests, the Lc1 load value (the first indication of cohesive failure (appearance of cracks)) was not observed, while the Lc2 (load responsible for the first delamination) and Lc3 (load at which the coating is severely delaminated from the substrate) were clearly observed on the scratch tracks. The Lc2 and Lc3 values of FastOs ${ }^{\circledR}$ BG- and Cu\&Ga-FastOs ${ }^{\circledR}$ BG-derived RF-MS coatings are presented in Figure 6b. The incorporation of $\mathrm{Cu}$ and $\mathrm{Ga}$ into the silica-rich SBG RF-MS layer led to a statistically significant $(p<0.05)$ increase of $\sim 15 \%$, with the Lc3 having a value of $4.9 \pm 0.47 \mathrm{~N}$. These values are similar to those (i.e., $\sim 5 \mathrm{~N}$ ) required to partially delaminate bioglass coatings of similar thickness, deposited by pulsed electron deposition (PED) from a silica-rich system (mol.\%: 
$\left.\mathrm{SiO}_{2}-47.2, \mathrm{Ca}-45.6, \mathrm{P}_{2} \mathrm{O}_{5}-2.6, \mathrm{~K}_{2} \mathrm{O}-4.6\right)$, and superior to those $(\sim 2 \mathrm{~N})$ of $600{ }^{\circ} \mathrm{C}$ heat-treated $45 \mathrm{~S} 5 \mathrm{PED}$ coatings [76].

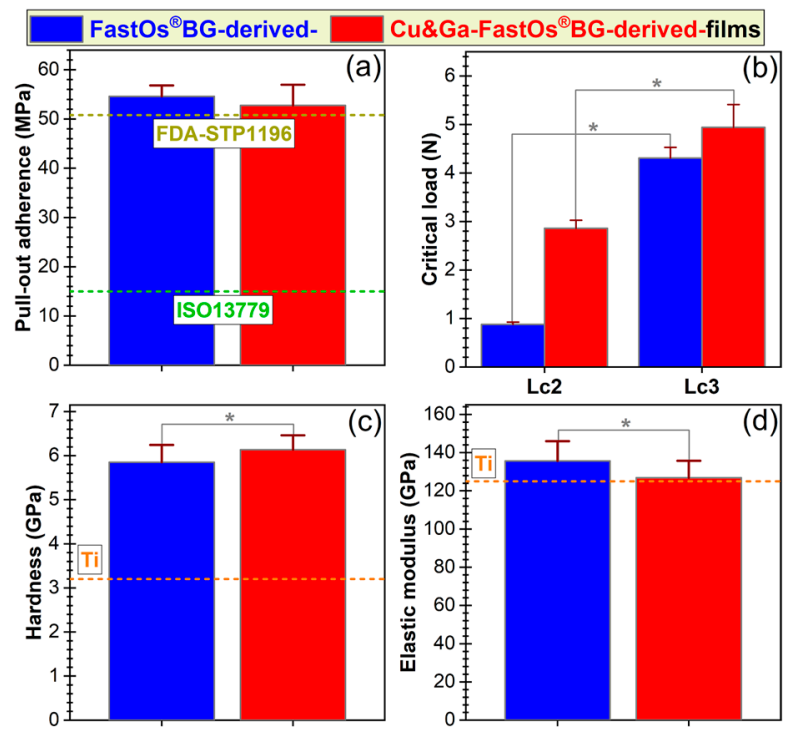

Figure 6. Summary of the mechanical performance of the SBG films in terms of (a) pull-off bonding strength (tensile), (b) scratch resistance, (c) hardness and (d) elastic modulus. ${ }^{*} p<0.05$, statistically significant differences, as determined by using an unpaired two-tailed Student's $t$-test.

The average hardness and elastic modulus values of the SBG coatings, determined by nano-indentation measurements, are presented in Figure $6 c, d$, respectively. The $\mathrm{Cu} \& \mathrm{Ga}$ doping moderately increased $(p<0.05)$ the hardness of the RF-MS film to a value of $\sim 6.1 \mathrm{GPa}$ (Figure $6 \mathrm{c}$ ), whilst the elastic modulus slightly decreased $(p<0.05)$ to $\sim 127$ GPa (Figure $6 \mathrm{~d}$ ). The nano-mechanical performances were similar $(\mathrm{E})$ or even higher $(\mathrm{H})$ with respect to titanium (e.g., $\mathrm{E} \approx 120 \mathrm{GPa}$, $\mathrm{H} \approx 3.6 \mathrm{GPa}[58,77])$.

Furthermore, the wear behaviour against a steel Rockwell tip, in linear motion, was assessed using the same MicroScratch tester. The wear tracks obtained on the uncoated (Figure 7a) and FastOs ${ }^{\circledR}$ BG-coated (Figure $7 \mathrm{~b}$ ) Ti substrate were severe, regardless of the applied load size $(1-5 \mathrm{~N})$, with increasing widths and depths of the wear track for higher applied loads. In contrast, the Cu\&Ga-FastOs ${ }^{\circledR}$ BG-derived coating showed a significantly enhanced wear behaviour (Figure 7c). For the lowest applied loads, namely 1, 2 and $3 \mathrm{~N}$, some wear grooves are visible on the surface, but to a much smaller extent compared to the uncoated and FastOs ${ }^{\circledR}$ BG-coated Ti substrate. Moreover, the width of the wear tracks on the Cu\&Ga-FastOs ${ }^{\circledR} B G$ coated sample is significantly smaller. This is a good indicator of an improved wear behaviour. No signs of delamination are visible for these loads. For higher applied loads, namely 4 and $5 \mathrm{~N}$, coating failures (delamination) are visible on the wear tracks, after 10 reciprocating passes. These values are in good agreement with the ones obtained during the adhesion tests. The wear coefficients determined on the basis of the wear volume loss under a load of $5 \mathrm{~N}$ as a function of the total test length are presented in Figure $7 \mathrm{~d}$. As hinted by the optical microscopy images, the wear coefficient is significantly improved by the application of the Cu\&Ga-FastOs ${ }^{\circledR}$ BG-derived coating. The so-called elastic strain to failure ratio $(\mathrm{H} / \mathrm{E})$ is a reliable indicator of wear resistance of materials, with values higher than 0.1 usually indicating a tough coating. Even though this value is not reached by the coatings presented herein, a slightly higher value of this ratio is exhibited by the Cu\&Ga-FastOs ${ }^{\circledR}$ BG-derived coating, in good agreement with the other wear parameters (wear coefficient, wear track width). These results are quite promising at this stage of the research development, especially considering that bio-glasses are relatively soft. 

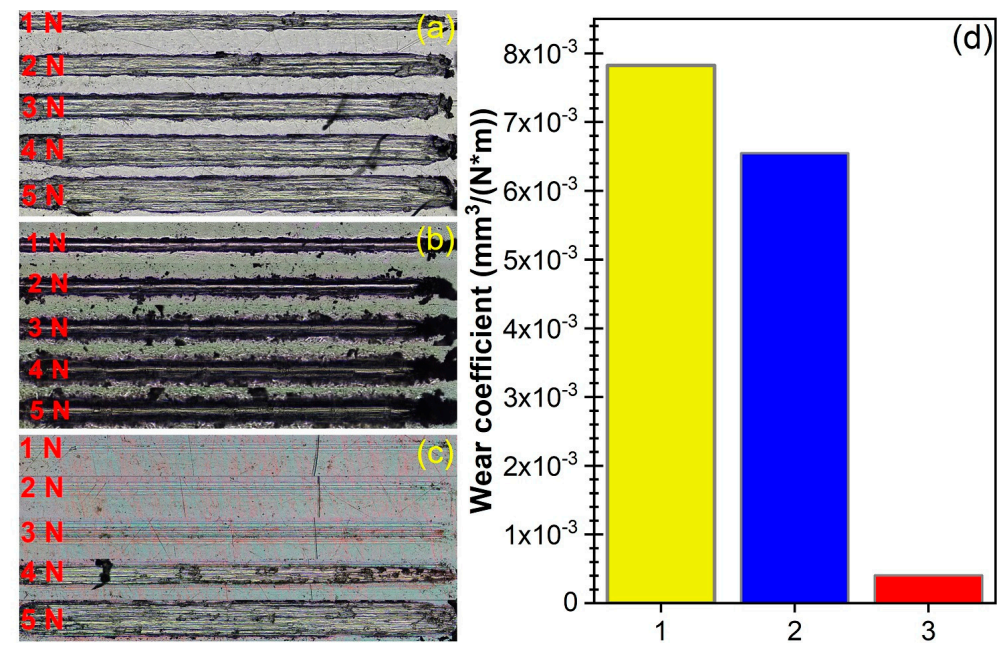

Figure 7. Optical microscopy images of the wear tracks recorded at five incremental load values (i.e., 1, 2, 3, 4 and $5 \mathrm{~N}$ ), with 10 passes per load at a displacement rate of $4 \mathrm{~mm} / \mathrm{min}$, in the case of the (a) bare and (b) FastOs ${ }^{\circledR}$ BG- and (c) Cu\&Ga-FastOs ${ }^{\circledR}$ BG-coated Ti substrate. (d) The wear coefficient determined for the three studied specimens under the load of $5 \mathrm{~N}$.

\subsection{In Vitro Preliminary Biological Evaluation}

\subsubsection{Antibacterial Efficacy at $24 \mathrm{~h}$}

Since dental implant coatings are the main targeted application, the antibacterial properties of the SBG films were preliminarily assessed against the Gram-positive S. aureus (ATCC ${ }^{\circledR}$ 6538) bacterial strain, both because of its presence in oral microbiota, and according to the ISO 22196:2011 recommendation [56]. 50,000 CFUs were seeded onto the samples and allowed to grow for $24 \mathrm{~h}$. The silica-rich FastOs ${ }^{\circledR} \mathrm{BG}$ did not impede the bacterial proliferation, whilst the Cu\&Ga-FastOs ${ }^{\circledR} \mathrm{BG}$ layer was found to reduce the bacterial development by 30 times with respect to the seeding CFU, and with 4 orders of magnitude with respect to the control situations (i.e., nutritive broth and bare substrate) (Figure 8). This output could be considered encouraging for combating the microbial infection at the implantation site. However, future dynamic studies need to be carried out, at several time intervals, and against a large palette of microbial strains, in order to fully probe and unveil the complete potential of such implant-type coatings.

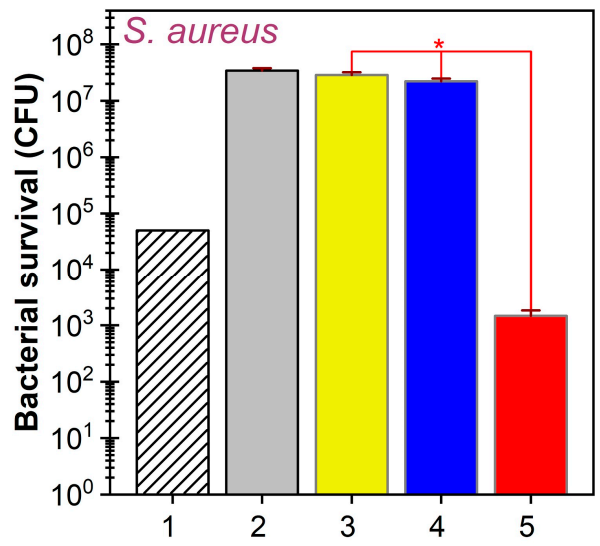

Figure 8. Antibacterial activity against $S$. aureus at $24 \mathrm{~h}$. The data are presented in logarithmic values of CFUs (bacterial survival). (1) seeded CFUs; (2) control = nutrient broth without sample; (3) bare and silica-rich (4) FastOs ${ }^{\circledR} \mathrm{BG}$ and (5) Cu\&Ga-FastOs ${ }^{\circledR} \mathrm{BG}$ coated substrate. ${ }^{*} p<0.05$, statistically significant differences, as determined by using an unpaired two-tailed Student's $t$-test. 


\subsubsection{Cytocompatibility Response at $24 \mathrm{~h}$}

The cytocompatibility of the samples was tested on NIH/3T3 fibroblast cell cultures (ATCC ${ }^{\circledR}$ CRL-1658 ${ }^{\mathrm{TM}}$ ). The cell proliferation was assessed by the MTS assay (Figure 9a), while the cell death was evaluated by a LDH test. Both silica-rich FastOs ${ }^{\circledR} \mathrm{BG}$ and Cu\&Ga-FastOs ${ }^{\circledR} \mathrm{BG}$ coatings elicited an excellent proliferation of cells, with values similar to those recorded on the standard substrate for cell cultures (i.e., polycarbonate for cell cultures) (Figure 9a). Furthermore, the $\mathrm{Cu} \& \mathrm{Ga}$-FastOs ${ }^{\circledR} \mathrm{BG}$-derived coatings showed lower values of $\mathrm{LDH}$ activity with respect to the FastOs ${ }^{\circledR}$ BG-derived ones, being situated closer to the ones recorded for the polycarbonate surface for cell cultures (Figure 9b). Thereby, it is advocated that the introduction of low concentrations of $\mathrm{Cu}$ and Ga into the thin FastOs ${ }^{\circledR}$ BG-derived films does not alter their cytocompatibility. When cultured on the silica-rich FastOs ${ }^{\circledR} \mathrm{BG}$ - and $\mathrm{Cu} \& \mathrm{Ga}-\mathrm{FastOs}^{\circledR}{ }^{\circledR} \mathrm{BG}$-derived coatings, the cells retained their characteristic morphology as seen in Figure 9c,d, respectively. Actin filaments grouped in bundles spanned the cells in a usual manner, whilst the nuclei retained their normal shape and chromatin condensation pattern.
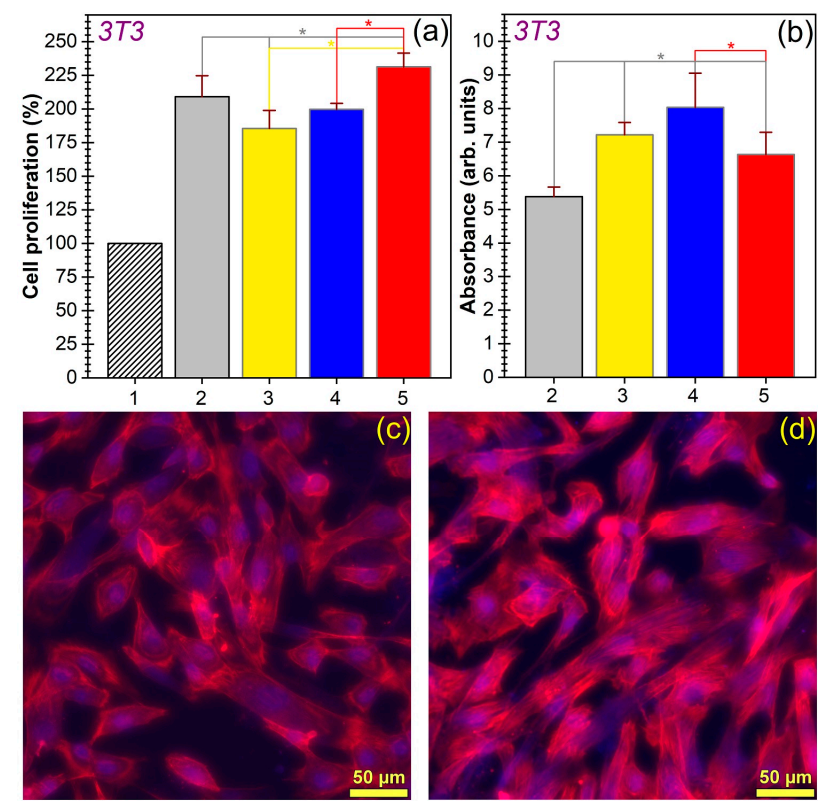

Figure 9. (a) Cell viability/proliferation assessed by MTS assay and (b) cytotoxicity assessed by LDH release after $24 \mathrm{~h}$. (1) seeded cells; (2) biological control-polycarbonate; (3) bare and silica-rich (4) FastOs ${ }^{\circledR} \mathrm{BG}$ and (5) $\mathrm{Cu} \& \mathrm{Ga}$-FastOs ${ }^{\circledR} \mathrm{BG}$ coated substrate. ${ }^{*} p<0.05$, statistically significant differences, as determined by using an unpaired two-tailed Student's $t$-test. Epi-fluorescence microscopy images revealing the morphology of $3 \mathrm{~T} 3$ fibroblast cells grown on the silica-rich: (c) FastOs ${ }^{\circledR} \mathrm{BG}$ and (d) Cu\&Ga-FastOs ${ }^{\circledR}$ BG films. The actin cytoskeleton was stained with phalloidin-AlexaFluor596 (red), whilst cell nuclei were counterstained with DAPI (blue). Objective: 40×. Magnification bar: $50 \mu \mathrm{m}$.

When analysing the antibacterial activity and cytocompatibility responses together, it is suggested that the application of layers of $\mathrm{Cu} \& \mathrm{Ga}$-FastOs ${ }^{\circledR} \mathrm{BG}$ on metallic endo-osseous implants represents a promising conceptual solution to minimize the risk of post-surgical bacterial infection.

\section{Conclusions}

Thin films of FastOs ${ }^{\circledR}$ BG alkali-free bioactive films co-doped with copper and gallium were successfully synthesised by radio-frequency magnetron sputtering.

The introduction of $\mathrm{Cu}$ and $\mathrm{Ga}$ induced a slight polymerization of the silica glass network of the films with respect to the undoped ones, having as effect a slight increase of the hardness (from $\sim 5.8$ to $\sim 6.1 \mathrm{GPa}$ ) and critical load of scratch delamination (from $\sim 4.3$ to $\sim 4.9 \mathrm{~N}$ ), and a decrease of the elastic modulus (from $\sim 136$ to $127 \mathrm{GPa}$ ), with the bonding strength being conserved ( $\sim 4 \mathrm{MPa}$ ). 
Furthermore, the Cu\&Ga-FastOs ${ }^{\circledR}$ BG-derived coating showed a significantly improved wear behaviour with respect to bare titanium and to the FastOs ${ }^{\circledR} B G$ coating.

While the contact angle with water is kept within the optimal $60-80^{\circ}$ range for cell adhesion, and the cytocompatibility of the $\mathrm{Cu} \&$ Ga silica-rich films remained unaltered, they manifested a marked antibacterial effect against the $S$. aureus strain, reducing its development by $\sim 4$ orders of magnitude after $24 \mathrm{~h}$.

Overall, these preliminarily mechanical and in vitro biological performances of $\mathrm{Cu} \& \mathrm{Ga}$ co-substituted silica-based bioactive glass films are testifying for their certain promise, which demands further exploration, on route to bio-functionalisation solutions capable to protect metallic endo-osseous implants against post-surgical microbial infection.

Author Contributions: Conceptualization, G.E.S., A.-C.P., C.B., T.T., and J.M.F.F.; Powder synthesis: H.R.F. and J.M.F.F.; Film fabrication: G.E.S., T.T., I.M.C., and A.C.S.; AFM, FTIR spectroscopy analyses: T.T., I.M.C., C.B., A.C.S., and G.E.S.; XPS investigations: C.C.N.; Surface energy investigations: I.Z.; EDXS measurements: G.P.-P.; Mechanical tests: D.C.; Biological assays: A.-C.P., L.E.I., and M.N.; writing—original draft preparation: G.E.S. and T.T.; writing - review and editing: T.T., G.E.S., A.-C.P., and J.M.F.F.; funding acquisition: G.E.S. All authors have read and agreed to the published version of the manuscript.

Funding: This research was funded by Romanian National Authority for Scientific Research and Innovation (CNCS-UEFISCDI) in the framework of project PN-III-P1-1.1-TE-2016-1501. J.M.F.F. is thankful for the financial support from CICECO-Aveiro Institute of Materials and FCT Ref. UID/CTM/50011/2019 grant, financed through the FCT/MCTES.

Acknowledgments: The authors thank for the financial support of the Romanian National Authority for Scientific Research and Innovation (CNCS-UEFISCDI) in the framework of project PN-III-P1-1.1-TE-2016-1501, and to the institutional Core Program 21N. This work was also developed within the scope of the project CICECO-Aveiro Institute of Materials, FCT Ref. UID/CTM/50011/2019, financed by national funds through the FCT/MCTES. NIMP authors acknowledge with thanks the acquisition of the Leica DM6 B fluorescence microscope in the framework of the Operational Programme Competitiveness project NANOBIOSURF-SMIS 103528 (2014-2020). D.C. acknowledges the structural funds project PRO-DD (POS-CCE, O.2.2.1., ID123, SMIS 2637, ctr. no 11/2009) for providing the CSM Instruments infrastructure used in this work.

Conflicts of Interest: The authors declare no conflict of interest.

\section{References}

1. Kawaguchi, K.; Iijima, M.; Endo, K.; Mizoguchi, I. Electrophoretic deposition as a new bioactive glass coating process for orthodontic stainless steel. Coatings 2017, 7, 199. [CrossRef]

2. Baino, F.; Hamzehlou, S.; Kargozar, S. Bioactive glasses: Where are we and where are we going? J. Funct. Biomater. 2018, 9, 25. [CrossRef] [PubMed]

3. Brunello, G.; Elsayed, H.; Biasetto, L. Bioactive glass and silicate-based ceramic coatings on metallic implants: Open challenge or outdated topic? Materials 2019, 12, 2929. [CrossRef] [PubMed]

4. Leite, Á.J.; Gonçalves, A.I.; Rodrigues, M.T.; Gomes, M.E.; Mano, J.F. Strontium-doped bioactive glass nanoparticles in osteogenic commitment. ACS Appl. Mater. Interfaces 2018, 10, 23311-23320. [CrossRef] [PubMed]

5. Fernandes, H.R.; Gaddam, A.; Rebelo, A.; Brazete, D.; Stan, G.E.; Ferreira, J.M.F. Bioactive glasses and glass-ceramics for healthcare applications in bone regeneration and tissue engineering. Materials 2018, 11, 2530. [CrossRef] [PubMed]

6. Prefac, G.A.; Milea, M.L.; Vadureanu, A.M.; Muraru, S.; Dobrin, D.I.; Isopencu, G.O.; Jinga, S.I.; Raileanu, M.; Bacalum, M.; Busuioc, C. $\mathrm{CeO}_{2}$ containing thin films as bioactive coatings for orthopaedic implants. Coatings 2020, 10, 642. [CrossRef]

7. Sergi, R.; Bellucci, D.; Cannillo, V. A comprehensive review of bioactive glass coatings: State of the art, challenges and future perspectives. Coatings 2020, 10, 757. [CrossRef]

8. Hench, L.L. The story of Bioglass ${ }^{\circledR}$. J. Mater. Sci. Mater. Med. 2006, 17, 967-978. [CrossRef]

9. Popa, A.C.; Fernandes, H.R.; Necsulescu, M.; Luculescu, C.; Cioangher, M.; Dumitru, V.; Stuart, B.W.; Grant, D.M.; Ferreira, J.M.F.; Stan, G.E. Antibacterial efficiency of alkali-free bio-glasses incorporating ZnO and/or $\mathrm{SrO}$ as therapeutic agents. Ceram. Int. 2019, 45, 4368-4380. [CrossRef] 
10. Stan, G.E.; Popescu, A.C.; Mihailescu, I.N.; Marcov, D.A.; Mustata, R.C.; Sima, L.E.; Petrescu, S.M.; Ianculescu, A.; Trusca, R.; Morosanu, C.O. On the bioactivity of adherent bioglass thin films synthesized by magnetron sputtering techniques. Thin Solid Film. 2010, 518, 5955-5964. [CrossRef]

11. Ciraldo, F.E.; Boccardi, E.; Melli, V.; Westhauser, F.; Boccaccini, A.R. Tackling bioactive glass excessive in vitro bioreactivity: Preconditioning approaches for cell culture tests. Acta Biomater. 2018, 75, 3-10. [CrossRef] [PubMed]

12. Bakry, A.S.; Tamura, Y.; Otsuki, M.; Kasugai, S.; Ohya, K.; Tagami, J. Cytotoxicity of 45 S5 bioglass paste used for dentine hypersensitivity treatment. J. Dent. 2011, 39, 599-603. [CrossRef] [PubMed]

13. Ferreira, J.M.F.; Rebelo, A. The key Features expected from a perfect bioactive glass-How Far we still are from an ideal composition? Biomed. J. Sci. Tech. Res. 2017, 1, 936-939. [CrossRef]

14. Cacciotti, I. Bivalent cationic ions doped bioactive glasses: The influence of magnesium, zinc, strontium and copper on the physical and biological properties. J. Mater. Sci. 2017, 52, 8812-8831. [CrossRef]

15. Kaya, S.; Cresswell, M.; Boccaccini, A.R. Mesoporous silica-based bioactive glasses for antibiotic-free antibacterial applications. Mater. Sci. Eng. C 2018, 83, 99-107. [CrossRef]

16. Tite, T.; Popa, A.C.; Balescu, L.M.; Bogdan, I.M.; Pasuk, I.; Ferreira, J.M.F.; Stan, G.E. Cationic substitutions in hydroxyapatite: Current status of the derived biofunctional effects and their in vitro interrogation methods. Materials 2018, 11, 2081. [CrossRef]

17. Drago, L.; Toscano, M.; Bottagisio, M. Recent evidence on bioactive glass antimicrobial and antibiofilm activity: A mini-review. Materials 2018, 11, 326. [CrossRef]

18. Jones, J.R. Review of bioactive glass: From Hench to hybrids. Acta Biomater. 2013, 9, 4457-4486. [CrossRef]

19. Valappil, S.P.; Ready, D.; Abou Neel, E.A.; Pickup, D.M.; Chrzanowski, W.; O’Dell, L.A.; Newport, R.J.; Smith, M.E.; Wilson, M.; Knowles, J.C. Antimicrobial gallium-doped phosphate-based glasses. Adv. Funct. Mater. 2008, 18, 732-741. [CrossRef]

20. Valappil, S.P.; Ready, D.; Abou Neel, E.A.; Pickup, D.M.; O’Dell, L.A.; Chrzanowski, W.; Pratten, J.; Newport, R.J.; Smith, M.E.; Wilson, M.; et al. Controlled delivery of antimicrobial gallium ions from phosphate-based glasses. Acta Biomater. 2009, 5, 1198-1210. [CrossRef]

21. Gross, T.M.; Lahiri, J.; Golas, A.; Luo, J.; Verrier, F.; Kurzejewski, J.L.; Baker, D.E.; Wang, J.; Novak, P.F.; Snyder, M.J. Copper-containing glass ceramic with high antimicrobial efficacy. Nat. Commun. 2019, 10, 1979. [CrossRef] [PubMed]

22. Pourshahrestani, S.; Zeimaran, E.; Kadri, N.A.; Gargiulo, N.; Samuel, S.; Naveen, S.V.; Kamarul, T.; Towler, M.R. Gallium-containing mesoporous bioactive glass with potent hemostatic activity and antibacterial efficacy. J. Mater. Chem. B 2016, 4, 71-86. [CrossRef] [PubMed]

23. Sanchez-Salcedo, S.; Malavasi, G.; Salinas, A.J.; Lusvardi, G.; Rigamonti, L.; Menabue, L.; Vallet-Regi, M. Highly-bioreactive silica-based mesoporous bioactive glasses enriched with gallium(III). Materials 2018, 11, 367. [CrossRef] [PubMed]

24. Wu, C.; Zhou, Y.; Xu, M.; Han, P.; Chen, L.; Chang, J.; Xiao, Y. Copper-containing mesoporous bioactive glass scaffolds with multifunctional properties of angiogenesis capacity, osteostimulation and antibacterial activity. Biomaterials 2013, 34, 422-433. [CrossRef]

25. Bari, A.; Bloise, N.; Fiorilli, S.; Novajra, G.; Vallet-Regí, M.; Bruni, G.; Torres-Pardo, A.; González-Calbet, J.M.; Visai, L.; Vitale-Brovarone, C. Copper-containing mesoporous bioactive glass nanoparticles as multifunctional agent for bone regeneration. Acta Biomater. 2017, 55, 493-504. [CrossRef]

26. Peszke, J.; Dulski, M.; Nowak, A.; Balin, K.; Zubko, M.; Sułowicz, S.; Nowak, B.; Piotrowska-Seget, Z.; Talik, E.; Wojtyniak, M.; et al. Unique properties of silver and copper silica-based nanocomposites as antimicrobial agents. RSC Adv. 2017, 7, 28092-28104. [CrossRef]

27. Ryan, E.J.; Ryan, A.J.; González-Vázquez, A.; Philippart, A.; Ciraldo, F.E.; Hobbs, C.; Nicolosi, V.; Boccaccini, A.R.; Kearney, C.J.; O’Brien, F.J. Collagen scaffolds functionalised with copper-eluting bioactive glass reduce infection and enhance osteogenesis and angiogenesis both in vitro and in vivo. Biomaterials 2019, 197, 405-416. [CrossRef]

28. Rau, J.V.; Curcio, M.; Raucci, M.G.; Barbaro, K.; Fasolino, I.; Teghil, R.; Ambrosio, L.; De Bonis, A.; Boccaccini, A.R. Cu-releasing bioactive glass coatings and their in vitro properties. ACS Appl. Mater. Interfaces 2019, 11, 5812-5820. [CrossRef]

29. Miola, M.; Verné, E. Bioactive and antibacterial glass powders doped with copper by ion-exchange in aqueous solutions. Materials 2016, 9, 405. [CrossRef] 
30. Hoppe, A.; Meszaros, R.; Stähli, C.; Romeis, S.; Schmidt, J.; Peukert, W.; Marelli, B.; Nazhat, S.N.; Wondraczek, L.; Lao, J.; et al. In vitro reactivity of Cu doped $45 \mathrm{~S} 5$ Bioglass ${ }^{\circledR}$ derived scaffolds for bone tissue engineering. J. Mater. Chem. B 2013, 1, 5659-5674. [CrossRef]

31. Romero-Sánchez, L.B.; Marí-Beffa, M.; Carrillo, P.; Medina, M.Á.; Díaz-Cuenca, A. Copper-containing mesoporous bioactive glass promotes angiogenesis in an in vivo zebrafish model. Acta Biomater. 2018, 68, 272-285. [CrossRef] [PubMed]

32. Yu, M.; Wang, Y.; Zhang, Y.; Cui, D.; Gu, G.; Zhao, D. Gallium ions promote osteoinduction of human and mouse osteoblasts via the TRPM7/Akt signaling pathway. Mol. Med. Rep. 2020, 22, 2741-2752. [CrossRef] [PubMed]

33. Wajda, A.; Goldmann, W.H.; Detsch, R.; Grünewald, A.; Boccaccini, A.R.; Sitarz, M. Structural characterization and evaluation of antibacterial and angiogenic potential of gallium-containing melt-derived and gel-derived glasses from $\mathrm{CaO}-\mathrm{SiO}_{2}$ system. Ceram. Int. 2018, 44, 22698-22709. [CrossRef]

34. Stan, G.E.; Morosanu, C.O.; Marcov, D.A.; Pasuk, I.; Miculescu, F.; Reumont, G. Effect of annealing upon the structure and adhesion properties of sputtered bio-glass/titanium coatings. Appl. Surf. Sci. 2009, 255, 9132-9138. [CrossRef]

35. ISO-International Organization for Standardization. ISO 13779-2:2018-Implants for SurgeryHydroxyapatite-Part 2: Thermally Sprayed Coatings of Hydroxyapatite; ISO-International Organization for Standardization: Geneva, Switzerland, 2018.

36. Callahan, T.J.; Gatenberg, J.B.; Sands, B.E. STP1196-Calcium phosphate (Ca-P) coating draft guidance for preparation of food and drug administration (FDA) submissions for orthopedic and dental endosseous implants. In Characterization and Performance of Calcium Phosphate Coatings for Implants; ASTM International: West Conshohocken, PA, USA, 1994; pp. 185-197.

37. Goel, A.; Kapoor, S.; Rajagopal, R.R.; Pascual, M.J.; Kim, H.-W.; Ferreira, J.M.F. Alkali-free bioactive glasses for bone tissue engineering: A preliminary investigation. Acta Biomater. 2012, 8, 361-372. [CrossRef]

38. Kapoor, S.; Goel, A.; Tilocca, A.; Dhuna, V.; Bhatia, G.; Dhuna, K.; Ferreira, J.M.F. Role of glass structure in defining the chemical dissolution behavior, bioactivity and antioxidant properties of zinc and strontium co-doped alkali-free phosphosilicate glasses. Acta Biomater. 2014, 10, 3264-3278. [CrossRef]

39. Popa, A.C.; Stan, G.E.; Besleaga, C.; Ion, L.; Maraloiu, V.A.; Tulyaganov, D.U.; Ferreira, J.M.F. Submicrometer hollow bioglass cones deposited by radio frequency magnetron sputtering: Formation mechanism, properties, and prospective biomedical applications. ACS Appl. Mater. Interfaces 2016, 8, 4357-4367. [CrossRef]

40. Popa, A.C.; Stan, G.E.; Husanu, M.A.; Mercioniu, I.; Santos, L.F.; Fernandes, H.R.; Ferreira, J.M.F. Bioglass implant-coating interactions in synthetic physiological fluids with varying degrees of biomimicry. Int. J. Nanomed. 2017, 12, 683-707. [CrossRef]

41. Cauchy, A.L. Sur la réfraction et la réflexion de la lumière. Bull. des Sci. Math. (Bull. Férussac) 1830, 14, 6-10.

42. Galca, A.C.; Stan, G.E.; Trinca, L.M.; Negrila, C.C.; Nistor, L.C. Structural and optical properties of c-axis oriented aluminum nitride thin films prepared at low temperature by reactive radio-frequency magnetron sputtering. Thin Solid Film. 2012, 524, 328-333. [CrossRef]

43. ISO-International Organization for Standardization. ISO 22309:2011-Microbeam Analysis—Quantitative Analysis Using Energy-Dispersive Spectrometry (EDS) for Elements with an Atomic Number of 11 (Na) or Above; ISO-International Organization for Standardization: Geneva, Switzerland, 2011.

44. Owens, D.K.; Wendt, R.C. Estimation of the surface free energy of polymers. J. Appl. Polym. Sci. 1969, 13, 1741-1747. [CrossRef]

45. Popa, A.C.; Stan, G.E.; Husanu, M.A.; Pasuk, I.; Popescu, I.D.; Popescu, A.C.; Mihailescu, I.N. Multi-layer haemocompatible diamond-like carbon coatings obtained by combined radio frequency plasma enhanced chemical vapor deposition and magnetron sputtering. J. Mater. Sci. Mater. Med. 2013, 24, 2695-2707. [CrossRef] [PubMed]

46. Visan, A.; Grossin, D.; Stefan, N.; Duta, L.; Miroiu, F.M.; Stan, G.E.; Sopronyi, M.; Luculescu, C.; Freche, M.; Marsan, O.; et al. Biomimetic nanocrystalline apatite coatings synthesized by matrix assisted pulsed laser evaporation for medical applications. Mater. Sci. Eng. B 2014, 181, 56-63. [CrossRef]

47. ISO_International Organization for Standardization. ISO 4624:2016_Paints and Varnishes_Pull-off Test for Adhesion; ISO-International Organization for Standardization: Geneva, Switzerland, 2016.

48. ASTM International. ASTM D4541-17 Standard Test Method for Pull-Off Strength of Coatings Using Portable Adhesion; ASTM International: West Conshohocken, PA, USA, 2017; pp. 1-16. 
49. Oliver, W.C.; Pharr, G.M. An improved technique for determining hardness and elastic modulus using load and displacement sensing indentation experiments. J. Mater. Res. 1992, 7, 1564-1583. [CrossRef]

50. Jacobs, R.; Meneve, J.; Dyson, G.; Teer, D.G.; Jennett, N.M.; Harris, P.; von Stebut, J.; Comte, C.; Feuchter, P.; Cavaleiro, A.; et al. A certified reference material for the scratch test. Surf. Coat. Technol. 2003, 174-175, 1008-1013. [CrossRef]

51. Ingelbrecht, C.; Jennett, N.; Jacobs, R.; Meneve, J. The Certification of Critical Coating Failure Loads: A Reference Material for Scratch Testing According to ENV 1071-3; European Commission: Luxembourg, 1994; ISBN 928946870X.

52. European Standards-CEN. EN1071-3/2005-Advanced Technical Ceramics-Methods of Test for Ceramic Coatings-Part 3: Determination of Adhesion and Other Mechanical Failure Modes by a Scratch Test; European Standards-CEN: Brussels, Belgium, 2005.

53. Meneve, J.; Havermans, D.; von Stebut, J.; Jennett, N.; Banks, J.; Saunders, S.; Camino, D.; Teer, D.; Andersson, P.; Varjus, S. The Scratch Test: Atlas of Failure Modes. In World Tribology Congress: Abstracts of Papers; Institution of Mechanical Engineers: London, UK, 1997; p. 495.

54. CDC. Available online: https://www.cdc.gov/infectioncontrol/pdf/guidelines/disinfection-guidelines-H.pdf (accessed on 3 November 2020).

55. WHO. Available online: https://apps.who.int/phint/pdf/b/7.5.9.5.8-Methods-of-sterilization.pdf (accessed on 3 November 2020).

56. ISO. ISO 22196:2011-Measurement of Antibacterial Activity on Plastics and Other Non-Porous Surfaces; ISO-International Organization for Standardization: Geneva, Switzerland, 2011.

57. ISO. ISO 10993-5:2009_Biological Evaluation of Medical Devices_Part 5: Tests for In Vitro Cytotoxicity; ISO-International Organization for Standardization: Geneva, Switzerland, 2009.

58. Popa, A.C.; Marques, V.M.F.; Stan, G.E.; Husanu, M.A.; Galca, A.C.; Ghica, C.; Tulyaganov, D.U.; Lemos, A.F.; Ferreira, J.M.F. Nanomechanical characterization of bioglass films synthesized by magnetron sputtering. Thin Solid Film. 2014, 553, 166-172. [CrossRef]

59. Besleaga, C.; Dumitru, V.; Trinca, L.M.; Popa, A.C.; Negrila, C.C.; Kołodziejczyk, Ł.; Luculescu, C.R.; Ionescu, G.C.; Ripeanu, R.G.; Vladescu, A.; et al. Mechanical, corrosion and biological properties of room-temperature sputtered aluminum nitride films with dissimilar nanostructure. Nanomaterials 2017, 7, 394. [CrossRef]

60. Chemical Books Phosphorus Pentoxide. Available online: https://www.chemicalbook.com/ ProductChemicalPropertiesCB9245033_EN.htm (accessed on 19 November 2020).

61. Wagner, C.D.; Riggs, W.M.; Davis, L.E.; Moulder, J.F.; Muilenberg, G.E. (Eds.) Handbook of X-Ray Photoelectron Spectroscopy: A Reference Book of Standard Spectra for Identification and Interpretation of XPS Data; Physical Electronics Division, Perkin-Elmer Corporation: Eden Prairie, MN, USA, 1992; ISBN 978-0-96-270262-4.

62. Carli, R.; Bianchi, C.L. XPS analysis of gallium oxides. Appl. Surf. Sci. 1992, 74, 99-102. [CrossRef]

63. Reed, T.B. Free Energy of Formation of Binary Compounds: An Atlas of Charts for High-Temperature Chemical Calculations; MIT Press: Cambridge, MA, USA, 1972; ISBN 978-0-26-218051-1.

64. Serra, J.; Gonzalez, P.; Liste, S.; Serra, C.; Chiussi, S.; Leon, B.; Perez-Amor, M.; Ylanen, H.O.; Hupa, M. FTIR and XPS studies of bioactive silica based glasses. J. Non-Cryst. Solids 2003, 332, 20-27. [CrossRef]

65. Nesbitt, H.W.; Bancroft, G.M.; Henderson, G.S.; Sawyer, R.; Secco, R.A. Direct and indirect evidence for free oxygen $\left(\mathrm{O}^{2-}\right)$ in MO-silicate glasses and melts $(\mathrm{M}=\mathrm{Mg}, \mathrm{Ca}, \mathrm{Pb})$. Am. Mineral. 2015, 100, 2566-2578. [CrossRef]

66. Ziemath, E.C.; Aegerter, M.A. Raman and Infrared investigations of glass and glass-ceramics with composition $2 \mathrm{Na}_{2} \mathrm{O} \cdot 1 \mathrm{CaO} \cdot 3 \mathrm{SiO}_{2}$. J. Mater. Res. 1994, 9, 216-225. [CrossRef]

67. Agathopoulos, S.; Tulyaganov, D.U.; Ventura, J.M.G.; Kannan, S.; Karakassides, M.A.; Ferreira, J.M.F. Formation of hydroxyapatite onto glasses of the $\mathrm{CaO}-\mathrm{MgO}-\mathrm{SiO}_{2}$ system with $\mathrm{B}_{2} \mathrm{O}_{3}, \mathrm{Na}_{2} \mathrm{O}, \mathrm{CaF}_{2}$ and $\mathrm{P}_{2} \mathrm{O}_{5}$ additives. Biomaterials 2006, 27, 1832-1840. [CrossRef] [PubMed]

68. Xu, X.; Li, J.; Yao, L. A study of glass structure in $\mathrm{Li}_{2} \mathrm{OSiO}_{2}, \mathrm{Li}_{2} \mathrm{OAl}_{2} \mathrm{O}_{3} \mathrm{SiO}_{2}$ and $\mathrm{LiAlSiON}$ systems. J. Non-Cryst. Solids 1989, 112, 80-84. [CrossRef]

69. Zhang, Z.; Wang, W.; Korpacz, A.N.; Dufour, C.R.; Weiland, Z.J.; Lambert, C.R.; Timko, M.T. Binary Liquid mixture contact-angle measurements for precise estimation of surface free energy. Langmuir 2019, 35, 12317-12325. [CrossRef] 
70. Lotfi, M.; Nejib, M.; Naceur, M. Cell Adhesion to Biomaterials: Concept of Biocompatibility. In Advances in Biomaterials Science and Biomedical Applications; Intech: Rijeka, Croatia, 2013; pp. 207-240. [CrossRef]

71. Popescu, A.C.; Florian, P.E.; Stan, G.E.; Popescu-Pelin, G.; Zgura, I.; Enculescu, M.; Oktar, F.N.; Trusca, R.; Sima, L.E.; Roseanu, A.; et al. Physical-chemical characterization and biological assessment of simple and lithium-doped biological-derived hydroxyapatite thin films for a new generation of metallic implants. Appl. Surf. Sci. 2018, 439, 724-735. [CrossRef]

72. Gentleman, M.M.; Gentleman, E. The role of surface free energy in osteoblast-biomaterial interactions. Int. Mater. Rev. 2014, 59, 417-429. [CrossRef]

73. Pešáková, V.; Kubies, D.; Hulejová, H.; Himmlová, L. The influence of implant surface properties on cell adhesion and proliferation. J. Mater. Sci. Mater. Med. 2007, 18, 465-473. [CrossRef]

74. Webb, K.; Hlady, V.; Tresco, P.A. Relative importance of surface wettability and charged functional groups on NIH 3 T3 fibroblast attachment, spreading, and cytoskeletal organization. J. Biomed. Mater. Res. 1998, 41, 422-430. [CrossRef]

75. Ng, C.H.; Rao, N.; Law, W.C.; Xu, G.; Cheung, T.L.; Cheng, F.T.; Wang, X.; Man, H.C. Enhancing the cell proliferation performance of NiTi substrate by laser diffusion nitriding. Surf. Coat. Technol. 2017, 309, 59-66. [CrossRef]

76. Bellucci, D.; Bianchi, M.; Graziani, G.; Gambardella, A.; Berni, M.; Russo, A.; Cannillo, V. Pulsed electron deposition of nanostructured bioactive glass coatings for biomedical applications. Ceram. Int. 2017, 43, 15862-15867. [CrossRef]

77. KYOCERA. Available online: https://kyocera-sgstool.co.uk/titanium-resources/titanium-informationeverything-you-need-to-know/titaniumproperties/\#: \{\}:text=It \1 $\backslash$ textquoterights\%20Young $\backslash \mathrm{T} 1 \backslash$ textquoterights $\% 20$ modulus $\% 20$ of $\% 20$ elasticity, shear $\% 20$ modulus $\% 20$ of $\% 2045 \% 20$ GPA ～(accessed on 3 November 2020).

Publisher's Note: MDPI stays neutral with regard to jurisdictional claims in published maps and institutional affiliations.

(C) 2020 by the authors. Licensee MDPI, Basel, Switzerland. This article is an open access article distributed under the terms and conditions of the Creative Commons Attribution (CC BY) license (http://creativecommons.org/licenses/by/4.0/). 